\title{
Reach Out and Reduce Prejudice: The Impact of Interpersonal Touch on Intergroup Liking
}

\section{Charles R. Seger , Eliot R. Smith , Elise James Percy \& Frederica R. Conrey}

To cite this article: Charles R. Seger , Eliot R. Smith , Elise James Percy \& Frederica R. Conrey (2014) Reach Out and Reduce Prejudice: The Impact of Interpersonal Touch on Intergroup Liking, Basic and Applied Social Psychology, 36:1, 51-58, DOI: 10.1080/01973533.2013.856786

To link to this article: http://dx.doi.org/10.1080/01973533.2013.856786

\section{Published online: 10 Feb 2014.}

\section{Submit your article to this journal $\llbracket$}

Џلll Article views: 987

Q View related articles $๘$

View Crossmark data $\asymp$ 


\title{
Reach Out and Reduce Prejudice: The Impact of Interpersonal Touch on Intergroup Liking
}

\author{
Charles R. Seger \\ University of East Anglia \\ Eliot R. Smith \\ Indiana University \\ Elise James Percy \\ University of Western Ontario \\ Frederica R. Conrey \\ Booz Allen Hamilton
}

\begin{abstract}
A brief, casual interpersonal touch results in positive behavior toward the toucher, presumably because touch is a cue to friendship. Research on intergroup contact shows that feelings of friendship toward an individual outgroup member reduce prejudice toward that entire group. Integrating these areas, we examined whether interpersonal touch by an outgroup member could reduce prejudice. In three replications in two studies, interpersonal touch decreased implicit, though not explicit, prejudice toward the toucher's group. Effects of interpersonal touch can extend beyond the toucher to others sharing the toucher's ethnicity, and findings suggest that such effects are automatic and outside conscious awareness.
\end{abstract}

"You wouldn't have dreamed of shaking hands, my father or me would not have dreamed of shaking hands with a black person."

Interpersonal touch is a hallmark of close relationships (Monsour, 1992) and both signifies and reinforces the bond between individuals who rely upon one another (see Fiske, 1992, 2004). When administered by an outgroup member, might this embodied cue to friendship reduce prejudice? To address this question, the present research investigated the effects of touch as literal "intergroup contact."

\section{EFFECTS OF INTERPERSONAL TOUCH}

Incidental touch, even between strangers, has repeatedly been shown to increase prosocial behavior and

Correspondence should be sent to Charles R. Seger, School of Psychology, University of East Anglia, Norwich Research Park, Norwich, NR4 7TJ, United Kingdom. E-mail: c.seger@uea.ac.uk compliance (see Gallace \& Spence, 2010). For example, customers who are touched by a waitress tend to give larger tips (e.g., Crusco \& Wetzel, 1984), and touched men cooperate more in a public goods game (Kurzban, 2001). These findings are consistent with developmental and neuropsychological evidence (e.g., Pearce, Martin, \& Wood, 1995; Weiss, Wilson, St. John Seed, \& Paul, 2001) that suggests humans are hardwired to respond positively to touch. Indeed, the effects of touch can occur without conscious awareness (Fisher, Rytting, \& Heslin, 1976). Research on touch has focused almost exclusively upon immediate behaviors toward the toucher. The growing evidence for relationships between interpersonal interactions and the larger intergroup context (see Brown \& Gaertner, 2001) suggests an intriguing and novel 
possibility: The effects of touch might extend beyond the toucher to the toucher's social group, and thereby influence intergroup evaluations.

\section{CONTACT AND PREJUDICE}

Evidence for the beneficial effects of intergroup contact on prejudice abounds. Hundreds of studies have supported Allport's (1954) proposition that contact (i.e., nonthreatening interaction) with outgroup members reduces prejudice (see Pettigrew \& Tropp, 2006). Pettigrew's (1998) review of the literature concluded that the factors that best facilitate prejudice reduction have one thing in common: They promote feelings of friendship, rather than mere acquaintanceship. Page-Gould, Mendoza-Denton, Alegre, and Siy (2010) demonstrated that closeness with an outgroup member brings that group closer to the psychological self, with positive outcomes for future interactions. Batson et al. (1997) demonstrated that feeling empathy for a member of a stigmatized group can improve attitudes toward the entire group. Of importance, feelings of closeness or friendship with an outgroup member can arise after a relatively brief period of contact. A brief programmed exchange of compliments and self-disclosure can reduce prejudice in roughly $30 \mathrm{~min}$ (Wright, Aron, McLaughlin-Volpe, \& Ropp, 1997). In fact, even imagining friendly intergroup contact with an outgroup member can reduce prejudice (Crisp \& Turner, 2009; Turner \& Crisp, 2010). Taken as a whole, this research demonstrates that even a small amount of actual or simulated interaction with an outgroup member can reduce prejudice.

\section{CONTACT AND THE EMBODIED MIND}

A growing literature is concerned with the critical role that the body plays in psychology. Building on and extending well-known links between bodily and mental states, the embodied cognition perspective is emerging as a theoretical framework in several areas of social and cognitive psychology (Barsalou, 2003; Barsalou, Niedenthal, Barbey, \& Ruppert, 2003; Niedenthal, Barsalou, Winkielman, Krauth-Gruber, \& Ric, 2005; Smith \& Semin, 2008). This perspective holds that our representations of concepts (even highly abstract ones) are not merely associated with but partially constituted by sensory-motor representations. Such notions of embodiment have implications for the effects of interpersonal touch. Specifically, Fiske $(1992,2004)$ regarded touch as signifying and helping to constitute Communal Sharing (CS) relationships. In such relationships, individuals share a close interpersonal bond, consider others to be like themselves, and freely share resources. Communal sharing is the main model of relating between mother and child and among close kin. Fiske (2004) considered touch to be an embodied cue to CS, as shown in a variety of relationships across disparate cultures. Warm touch shows that interpersonal boundaries are softened and signals the key aspect of a CS relationship, that people are treated as undifferentiated and equivalent. This involves the merging of mental representations of the self and other (Aron, Aron, Tudor, \& Nelson, 1991), which enables the sharing that characterizes close communal relationships. The other person is treated as an extension of the self, in a very real way.

Notably, elements of CS relationships occur in larger groups, when a valued membership is shared. Selfcategorization theory (Turner, Hogg, Oakes, Reicher, \& Wetherell, 1987) predicts that group members see themselves not as individuals but as exemplars of a social category; this leads to behaving as if they and others are interchangeable. In such a situation, mental representations of the self and ingroup merge (Smith \& Henry, 1996), facilitating collective action (Tropp \& Wright, 2001), shared emotions (Smith, Seger, \& Mackie, 2007) and sacrificing for the benefit of the group or for other ingroup members.

Thus, if touch induces a CS relationship (or merging of self and other representations) with another individual, it may indirectly produce merging of the self with the other's group membership - even if that is an outgroup for the individual. The result is predicted to be more favorable responses to the outgroup, that is, a reduction of prejudice. This argument parallels that made by Wright et al. (1997), who showed that even knowing that another ingroup member has an outgroup friend can indirectly reduce prejudice.

\section{THE PRESENT RESEARCH}

To summarize, interpersonal touch often directly increases recipients' positivity or compliance toward the toucher, and intimate relationships and friendships are marked, maintained, and strengthened by embodied interpersonal touch. Evidence that intergroup friendship can reduce prejudice has been building since Allport (1954). Hence, interpersonal touch may serve as an embodied cue to an actual friendship with an outgroup member, not unlike other indirect manipulations of intergroup contact (e.g., Turner \& Crisp, 2010). In the two studies reported here, we investigated the potential for interpersonal touch by an outgroup member to reduce prejudice toward the toucher's entire social group.

\section{STUDY 1}

The first study tested our hypothesis that interpersonal touch by an outgroup member can increase positivity toward the toucher's group as a whole, using both explicit 
and implicit attitude measures (the latter refers to more spontaneous or automatic evaluative associations; see Greenwald \& Banaji, 1995; Dovidio, Kawakami, Johnson, Johnson, \& Howard, 1997).

\section{Participants}

Participants were 78 non-Black Indiana University undergraduates who received course credit for completing this study. Data from two participants were not used due to an error rate of greater than $50 \%$ on the priming task, leaving a total sample size of 76 ( 40 female). ${ }^{1}$

\section{Procedure}

Participants signed up for the study through an online booking system. They were informed that the study would include a variety of short tasks on the computer. Upon arriving for the experiment, participants were greeted by a female African American experimenter. To heighten participants' awareness of her racial identity, the experimenter wore a Black History Month T-shirt. Participants were seated in individual cubicles in front of their computers. Those randomly assigned to the "touch" condition were given a casual, light touch on the shoulder for 1 to $2 \mathrm{~s}$ as the experimenter leaned over the participant to type in the participant number. Those in the "no touch" condition typed in their participant numbers themselves while the experimenter stood immediately behind them without touching them. To ensure that the experimenter treated members of both groups equally, random assignment occurred immediately before the touch manipulation was to occur, when the experimenter blindly chose either a blue or black pen from her pocket, and the experimenter left the cubicle immediately after the manipulation to limit the amount of her interaction with participants. The experimenter was blind to the experimental hypothesis.

For the remainder of the session, the computer collected all dependent measures. The first measure was a two-question scale of perceived similarity to the experimenter, who was identified in the question by first name and as "your experimenter." The responses ranged from 1 (not close at all, nothing in common) to 5 (extremely close, a great deal in common). The computer informed participants that we were interested in the answers to those questions before the larger experiment began.

Implicit attitudes were assessed via an evaluative priming task of 144 trials (see Fazio, 2001). On each trial, participants categorized a word as either good (e.g., "pleasant") or bad (e.g., "disaster") immediately after a

\footnotetext{
${ }^{1}$ Unfortunately, specific racial information was not collected; however, it was confirmed that all participants were non-Black. The participant pool at this university is over $85 \%$ White.
}

photographic prime flashed on the screen for $150 \mathrm{~ms}$. Participants were told to ignore these photographs. Experimental primes consisted of facial photographs of Black and White men and women, as well as a photo of the experimenter herself. Participants were instructed that we were interested in how people categorize words and that they were to try to be as fast and accurate as possible.

Following the evaluative priming task, participants reported their evaluations of African Americans, Caucasians, men, women, themselves, and the experimenter (again identified by name) on "feeling thermometer" scales ranging from 0 (dislike a great deal) to 9 (like a great deal). They also completed a slightly modified version of the Symbolic Racism 2000 Scale (SRS; Henry \& Sears, 2002), a self-report measure tapping politically oriented attitudes toward Blacks. For example, one item on the scale is "Over the past few years, blacks have gotten more economically than they deserve." After completing these measures, subjects were debriefed and compensated with course credit.

\section{Results}

Implicit prejudice. Response times for the evaluative priming task were used to assess the influence of the touch manipulation on implicit attitudes. The basic assumption of this measure is that latencies to report the target word's valence are shortest when target valence is consistent with that of the prime (Fazio \& Olson, 2003). The difference between response times for negative targets and positive targets can be used to gauge implicit evaluations of each prime type. In keeping with traditional treatment of reaction time data for speeded response tasks, cutoffs were applied to individual trials such that incorrect responses, responses faster than $300 \mathrm{~ms}$, and responses slower than 2,000 ms were eliminated from analysis (Devine, Plant, Amodio, HarmonJones, \& Vance, 2002). We then calculated the response time indices for each type of prime. To do so, we isolated responses made after each individual category of primes (e.g., women, Black targets, White targets) and then subtracted the average response time for positive words from that of negative words. This procedure created an index for which larger numbers indicated greater positivity toward that type of prime. Preliminary analyses showed that there were no effects of, or interactions with, participant gender on any of the dependent measures, and so participant gender effects are not discussed further.

Consistent with our central prediction, touch by an African American experimenter led to more positive implicit attitudes toward Blacks, with the response time index significantly more positive in the touch $(M=48.7$, $S D=61.5)$ than in the no-touch condition $(M=10.8$, 


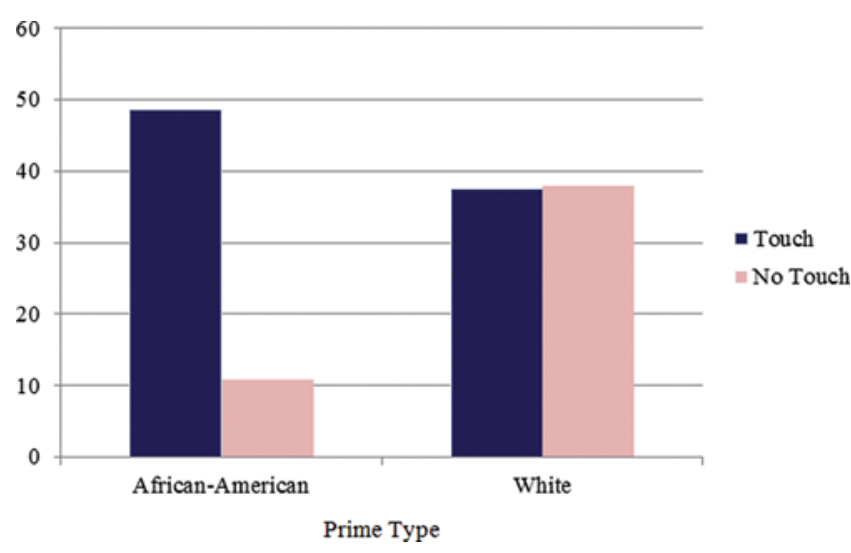

FIGURE 1 Mean evaluative priming scores for African American and White primes by touch condition, Study 1. Note. Higher numbers indicate increased positivity toward each prime type. (color figure available online)

$S D=73.8), F(1,74)=5.65, p=.02$, as seen in Figure 1 . To examine whether touch had unpredicted effects on implicit attitudes for other social categories, we repeated this analysis for White, male primes, and female primes, which showed no significant effects $(F s<1.25) .{ }^{2}$ Finally, the implicit measure of evaluation of the experimenter herself was in the expected direction but not significant (touch: $M=44.92, S D=147.66$; no touch: $M=10.91$, $S D=178.02 ; F<1)$.

Explicit prejudice. The SRS was recoded such that higher numbers indicated greater positivity toward African Americans. The two measures of explicit attitudes toward Blacks (SRS and feeling thermometer) correlated at $r=.32(p<.01)$. However, neither of these measures correlated with implicit attitudes toward Blacks (both $r \mathrm{~s}<.14$ ). This result is consistent with other research in the domain of racial attitudes showing that implicit and explicit responses are often dissociated (Fazio \& Olson, 2003; Nosek, 2005). On the SRS, similarity measures, and all the feeling thermometers but one, the touch manipulation produced no significant effects or interactions $\left(F_{\mathrm{S}}<1.25\right)$; the single exception was that touched participants rated men less favorably than did nontouched participants (touch: $M=5.30$, $S D=1.97$; no touch: $M=6.56, S D=1.72), F(1,74)=8.72$, $p<.01$. This effect was unpredicted and did not replicate in the subsequent study. Thus, it is not discussed further.

\footnotetext{
${ }^{2} \mathrm{~A}$ repeated measures analyses of variance showed that gender of the prime did not significantly moderate the effects of touch on evaluations. The between condition differences were in the same direction for Black women (touch: $M=61.07, S D=14.81$; no touch: $M=3.28$, $S D=12.97$ ) and Black men (touch: $M=34.73, S D=16.73$; no touch: $M=17.24, S D=14.66), F(1,74)=2.14, p=.15$.
}

\section{Discussion}

Study 1 demonstrated that a brief, casual touch by an African American reduced implicit prejudice toward African Americans, but there was no evidence for a reduction in explicit prejudice (a finding to be discussed in more detail later) or for changes in evaluations of Caucasians.

These results constitute the first demonstration of interpersonal touch affecting implicit evaluations, and the first evidence that a minimal embodied action can reduce implicit prejudice toward a social group as a whole. Touch reduced implicit prejudice toward the experimenter's ethnic group without significantly changing implicit attitudes toward the experimenter herself, but this finding is likely explained by the fact that the experimenter's photograph was presented to each participant on only six trials of the implicit task to reduce suspicion among participants. The results for evaluative priming trials following the experimenter's photograph were very similar to those for Blacks as a whole, but the statistical power for this test was very low.

In Study 2, we aimed to replicate and extend this basic effect, using different touchers and an additional ethnic group. To examine a more natural categorization, we did not have the Study 2 experimenters wear clothing that reflected their ethnic identities. Study 2 also added a measure of participants' awareness of the touch. Although some researchers have found that conscious awareness of touch increases compliance (Joule \& Guéguen, 2007), other research suggests that touch does not require conscious attention to affect social evaluations and behavior. For example, a 1-s shoulder touch has been shown to increase compliance, despite virtually universal unawareness of the touch when participants were asked at the end of the experiment (Patterson, Powell, \& Lenihan, 1986). Silverthorne, Noreen, Hunt, and Rota (1972) also found significant effects of touch despite a $12 \%$ awareness rate. Two published studies have specifically compared those who remembered a touch against those who did not, in the contexts of evaluative responses (Fisher et al., 1976) and compliance (Guéguen, 2002). Both studies showed positive effects of touch, yet neither showed significant differences between those who could recall the touch and those who could not. Based on these findings, we predicted that the effects of touch on prejudice would be obtained regardless of awareness.

\section{STUDY 2}

\section{Participants}

Participants signed up for the study though an online booking system. They were told that the study would consist of a variety of response time tasks and 
computer-administered questionnaires. Participants were 155 Indiana University undergraduates who received course credit for completing this study. Data from 18 additional participants in the Asian experimenter condition were not used in the response time analysis due to a computer error that led them to complete the wrong priming task. We excluded from analysis African American and Asian participants who encountered a same-race experimenter and two subjects in the African American condition who provided incomplete data, leaving total sample sizes of 81 (62 female, 83\% Caucasian) and 47 (33 female, 82\% Caucasian) for the African American and Asian experimenters, respectively.

\section{Procedure and Materials}

Participants were greeted by either an African American or Asian female experimenter, who administered the touch manipulation in exactly the same manner as in Study 1. Experimenters were blind to the experimental hypothesis. Participants then completed measures of their self-reported emotional responses to scenarios in which fictitious characters experienced various positive or negative events. These exploratory measures did not assess prejudice (overall evaluations of any ethnic groups), so they are irrelevant to the hypothesis of this article and are not discussed here. ${ }^{3}$ Participants then completed an evaluative priming measure very similar to the one used in the initial study, employing African American and White primes for participants run by the African American experimenter, and Asian and White primes for participants run by the Asian experimenter.

This experiment also employed a measure of awareness of the touch. After the experiment (but prior to the debriefing), the experimenter asked participants, "By the way, do you recall if I happened to touch you at the beginning of the experiment?"

\section{Results}

Implicit prejudice. Scores for the evaluative priming task were calculated in the same manner as in Study 1, with higher scores indicating more favorable attitudes toward each group. We conducted separate 2 (touch) $\times 2$ (participant gender) analyses of variance for participants in the African American and Asian experimenter

\footnotetext{
${ }^{3}$ Specifically, participants read three brief scenarios in which targets were treated potentially unfairly (e.g., passed over for promotion). Participants rated how aggressive, angry, anxious, cheerful, depressed, happy, helpless, outraged, sad, and uneasy they felt following each scenario, using 9-point Likert scales (ranging from 1 to 9), with instructions to indicate how much they feel each emotion "right now." These scenarios were related to exploratory hypotheses regarding potential emotional consequences of touch.
}

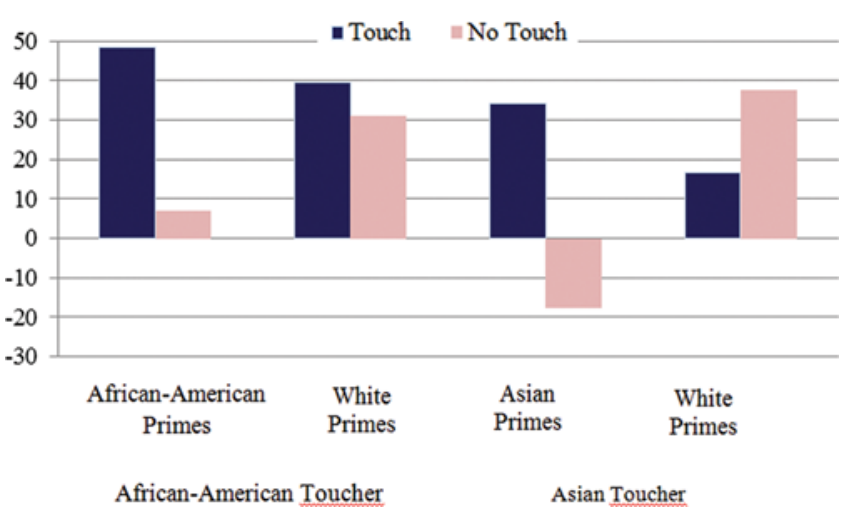

FIGURE 2 Mean evaluative priming scores for African American and White primes in the African American toucher condition, and for Asian and White primes in the Asian toucher condition, Study 2. Note. Higher numbers indicate increased positivity toward each prime type. (color figure available online)

conditions; separate analyses were used because these two groups of participants completed different priming tasks.

As shown in Figure 2, in the African American condition, evaluations of Blacks became more positive when participants were touched $(M=48.51, S D=61.82)$, compared to the no touch condition $(M=7.07, S D=75.13)$, $F(1,77)=13.29, p<.001$. This effect is qualified by an interaction between touch and participant gender, $F(1,77)=5.65, p=.02$. Simple effects analyses showed that touch significantly increased positivity for men (touch: $M=60.30, S D=70.23$; no touch: $M=-45.34$, $S D=77.01), F(1,17)=9.68, p<.01$, but not for women (touch: $M=44.72, S D=59.78$; no touch: $M=22.48$, $S D=68.27), F(1,60)=1.82, p=.18$. Evaluations of Whites were not affected by touch (touch: $M=39.44, S D=71.31$; no touch: $M=30.99, S D=75.37, F<1)$. Although implicit attitudes toward men were unaffected, participants were more positive toward women on the whole when touched by the African American experimenter, (touch: $M=61.70$, $S D=75.37$; no touch: $M=16.60, S D 70.57), F(1,80)=7.82$, $p=.006){ }^{4}$ This effect was not qualified by participant gender $(F<1)$.

In the Asian condition, participant gender showed no main effect or interaction, so it was dropped from further analysis. Evaluations of Asians became more positive in the touch condition (touch: $M=34.17, S D=91.68$; no touch: $M=-17.62, S D=68.72), F(1,45)=4.83, p=.03$. Evaluations of Whites were not affected by touch (Touch: $M=16.78, S D=85.92$; no touch: $M=37.45, S D=74.28$ ), $F<1$. Touch did not have an effect on evaluations of

\footnotetext{
${ }^{4}$ Evaluative priming scores for Black female primes (touch: $M=44.24, S D=107.76$; no touch: $M=4.58, S D=101.88$ ) and Black male primes (touch: $M=53.57, S D=82.66$; no touch: $M=10.50$, $S D=110.10)$ were not differentially affected by touch condition $(F<1)$.
} 
women as a whole (touch: $M=25.53, S D=83.13$; no touch: $M=13.80, S D=77.52), F<1 .^{5}$

Awareness of touch. We also assessed whether implicit evaluations of participants in the touch condition depended on whether they remembered the touch. For the African American experimenter, those who remembered $(N=14)$ and those who did not remember $(N=23)$ did not differ in their evaluations $(F \mathrm{~s}<1)$. For the Asian experimenter, the difference between those who remembered and those who did not was marginally significant, such that there was a tendency for individuals' implicit attitudes toward Asians to be more positive when they did not remember the touch (not remembered: $M=62.35, S D=93.38, N=13$; remembered: $M=-2.45$, $S D=78.53, N=10), F(1,21)=3.29, p=.09$.

\section{GENERAL DISCUSSION}

Across two studies, the key effect was replicated three times: Brief, casual interpersonal touch by an outgroup member increased implicit positivity toward the toucher's ethnic group as a whole. Evaluations of Whites were not affected. This was true for two different African American touchers (in Studies 1 and 2) and an Asian toucher (Study 2). Previous research shows that the mere presence of an outgroup experimenter can reduce prejudice (Lowery, Hardin, \& Sinclair, 2001). In our studies, interpersonal touch produced an effect above and beyond the effect of the mere presence of the experimenter in the no-touch control conditions. Although research on the intergroup contact effect (Pettigrew \& Tropp, 2006) has demonstrated the positive interpersonal interaction generalizes to the larger group, this is the first investigation to extend this effect to a minimal embodied cue such as touch.

Moreover, the results suggest that touch influences low-level evaluations of the experimenter's racial group, rather than operating through conscious processes or demand characteristics. Two aspects of the data support this conclusion. First, the effect appears on an implicit measure (evaluative priming) but not on explicit measures. Although no measure is completely process pure, this pattern suggests that deliberatively driven attitude change is not primarily responsible for the effects of touch. Second, the effect is similar in magnitude whether or not participants recall being touched. This pattern, like the first, is inconsistent with an explicit demand interpretation.

We can also be confident that the effects are dependent on the race of the toucher and are not mediated by some

${ }^{5}$ Furthermore, evaluative priming scores for Asian female primes (touch: $M=45.35, S D=111.56$; no touch: $M=-7.80, S D=104.51$ ) and Asian male primes (touch: $M=22.01, S D=127.52$; no touch: $M=-26.12$, $S D=88.58)$ were not differentially affected by touch condition $(F<1)$. nonspecific effect of interpersonal touch, such as global positive mood. Touch improved evaluations of primes who shared the experimenter's race but not those who did not, rather than showing the general increase in positivity toward all groups that might be expected to result from a mood effect. This pattern in the results also renders extremely implausible the suggestion that touch by anyone (even an experimenter sharing the participant's race) would have produced the prejudice reduction effects shown here. Such a suggestion rests on the assumption that touch would improve implicit evaluations of others who do not share the toucher's racial group membership, something we have no evidence for in three replications. This pattern corresponds with Lowery et al. (2001), who showed specific implicit prejudice reduction effects in the presence of a Black but not a White experimenter.

Although previous research has demonstrated that interpersonal touch has a positive effect on behaviors toward the individual toucher, our studies take this effect beyond the interpersonal to the level of social groups. As previous research shows, friendly intergroup contact with an outgroup member reduces prejudice. The current research shows that touch, an embodied cue to friendship, can also produce such an effect.

We found that touch reduced implicit but not explicit prejudice. Implicit and explicit racial attitudes are often dissociated (see Fazio \& Olson, 2003; Nosek, 2005), and there are several reasons why touch in particular may affect implicit and explicit responses differently. First, there is evidence that such attitudes are influenced by different kinds of manipulations. The vast literature on contact and prejudice (Pettigrew \& Tropp, 2006) relies heavily on explicit measures and generally finds favorable contact effects, but self-presentational biases or a desire to report consistent attitudes may make it difficult for subtle or short-term manipulations of contact (such as touch) to change explicit responses. Implicit responses may be more easily influenced by subtle features of the environment. For example, mental imagery of intergroup contact (Turner \& Crisp, 2010) has been shown to reduce implicit prejudice. Several studies find that implicit attitudes toward racial groups are quite malleable (e.g., Blair, 2002), and our findings support this notion.

A second possible reason for this implicit-explicit dissociation is recent evidence suggesting that intergroup contact influences implicit and explicit prejudice through different processes (Turner, Hewstone, \& Voci, 2007). Specifically, explicit prejudice is reduced through the mediation of several interpersonal processes, such as reduction of anxiety and mutual self-disclosure, whereas contact's effect on implicit measures is direct and does not depend on these mediators. Given such findings, a brief interpersonal touch is unlikely to produce meaningful changes in anxiety or self-disclosure, and therefore is unlikely to influence explicit attitudes. 
A minor limitation is that all of our touchers were female. Although the use of female touchers was sufficient to address our major theoretical issues, touch by a man may have differing effects, as women are generally more oriented toward interpersonal touch (Derlega, Lewis, Harrison, Winstead, \& Costanza, 1989). Men may be less likely to feel comfortable with a touch by an unfamiliar man, and women may perceive a shoulder touch by a man as suggestive. However, to the extent that these limitations can be overcome (or for participants not bothered by these issues), touch by a man should have the same general effect as in these studies.

In our studies, touch by the female experimenters generally (in two of three cases) did not have the same positive effects on evaluations of women as it did for the evaluations of the toucher's ethnic group. The effect of touch on evaluations of the toucher's racial group was not driven solely by increased positivity toward female group members. We expect these findings are largely a function of category salience. Specifically, the experimenter's ethnicity was likely a much more salient categorization than her gender (see Mitchell, Nosek, \& Banaji, 2003). Supporting this, the student population from which participants were sampled (a Midwestern American university) is $51 \%$ female but only $4.3 \%$ African American and 3.9\% Asian. It is quite plausible that if gender had been the more salient categorization, prejudice reduction would have been greater for the experimenter's gender category than the associated racial category.

The positive effects of touch surely have limiting conditions. Touch that clearly violates societal norms or rigid hierarchies is likely to have negative consequences. In a situation of clear status or dominance relationships, touch can take on other meanings (indicating asymmetrical status rather than friendship; Summerhays \& Suchner, 1978). In our studies, participants and experimenters were of similar status (i.e., all were undergraduate students and the experimenters were dressed casually). Finally, the touch in these studies was brief and casual; other forms of touch (e.g., sexual touch) might be regarded as inappropriate and likely would have negative effects on attitudes.

\section{Conclusion}

We have demonstrated that a simple and subtle touch can decrease prejudice toward an entire ethnic group. This novel finding has broad implications, for touch is a ubiquitous aspect of interpersonal experience. Existing work indicates that a restaurant server who touches patrons may receive larger tips, but our work might predict a far broader effect as well: increased positivity toward the server's social category as a whole. Ultimately, this research suggests that even minor bodily overtures of friendship can have far-reaching consequences, not only for our interactions with the toucher as an individual but also for the broader intergroup context that is the backdrop for all our interactions.

\section{ACKNOWLEDGMENTS}

We are grateful to D. Austin Chapman, Ashley Waggoner Denton, and Ishani Banerji for their advice and assistance.

\section{FUNDING}

This work was facilitated by NSF Grant BCS-0719876 to Eliot R. Smith.

\section{REFERENCES}

Allport, G. W. (1954). The nature of prejudice. Reading, MA: Addison-Wesley.

Amos, D. (Narrator). (2001, October). Remembering Jim Crow [Radio broadcast episode]. Washington, DC: National Public Radio.

Aron, A., Aron, E. N., Tudor, M., \& Nelson, G. (1991). Close relationships as including other in the self. Journal of Personality and Social Psychology, 60, 241-253.

Barsalou, L. W. (2003). Situated simulation in the human conceptual system. Language and Cognitive Processes, 18, 513-562.

Barsalou, L. W., Niedenthal, P. M., Barbey, A. K., \& Ruppert, J. A. (2003). Social embodiment. In B. H. Ross (Ed.), The psychology of learning and motivation: Advances in research in theory, 43 (pp. 43-93). New York, NY: Elsevier.

Batson, C. D., Polycarpou, M. P., Harmon-Jones, E., Imhoff, H. J., Mitchener, E. C., Bednar, L. L., ... Highberger, L. (1997). Empathy and attitudes: Can feeling for a member of a stigmatized group improve feelings toward the group? Journal of Personality and Social Psychology, 72, 105-118.

Blair, I. V. (2002). The malleability of automatic stereotypes and prejudice. Personality and Social Psychology Review, 6, 242-261.

Brown, R., \& Gaertner, S. V. (Eds.). (2001). Blackwell handbook of social psychology: Intergroup relations. Oxford, UK: Blackwell.

Crisp, R. J., \& Turner, R. N. (2009). Can imagined interactions produce positive perceptions?: Reducing prejudice through simulated social contact. American Psychologist, 64, 231-240. doi: 10.1037/a0014718

Crusco, A. H., \& Wetzel, C. G. (1984). The Midas Touch: The effects of interpersonal touch on restaurant tipping. Personality and Social Psychology Bulletin, 10, 512-517. doi:10.1177/0146167284104003

Derlega, V. J., Lewis, R. J., Harrison, S., Winstead, B. A., \& Costanza, R. (1989). Gender differences in the initiation and attribution of tactile intimacy. Journal of Nonverbal Behavior, 13, 83-96. doi: 10.1007/ BF0090792

Devine, P. G., Plant, E. A., Amodio, D. M., Harmon-Jones, E., \& Vance, S. L. (2002). The regulation of explicit and implicit race bias: The role of motivations to respond without prejudice. Journal of Personality and Social Psychology, 82, 835-848.

Dovidio, J. F., Kawakami, K., Johnson, C., Johnson, B., \& Howard, A. (1997). On the nature of prejudice: Automatic and controlled processes. Journal of Experimental Social Psychology, 33, 510-540.

Fazio, R. H. (2001). On the automatic activation of associated evaluations: an overview. Cognition and Emotion, 15, 115-141. 
Fazio, R. H., \& Olson, M. A. (2003). Implicit measures in social cognition research: Their meaning and uses. Annual Review of Psychology, 54, 297-327. doi:10.1146/annurev.psych.54.101601.145255

Fisher, J. D., Rytting, M., \& Heslin, R. (1976). Hands touching hands: Affective and evaluative effects of an interpersonal touch. Sociometry, $39,416-421$.

Fiske, A. P. (1992). The four elementary forms of sociality: Framework for a unified theory of social relations. Psychological Review, 99, 689-723. doi:10.1037/0033-295X.99.4.689

Fiske, A. P. (2004). Four modes of constituting relationships: Consubstantial assimilation; space, magnitude, time, and force; concrete procedures; abstract symbolism. In N. Haslam (Ed.), Relational models theory: A contemporary overview (pp. 61-146). Mahwah, NJ: Erlbaum

Gallace, A., \& Spence, C. (2010). The science of interpersonal touch: An overview. Neuroscience and Biobehavioral Reviews, 34, 246-259.

Greenwald, A. G., \& Banaji, M. R. (1995). Implicit social cognition: Attitudes, self-esteem, and stereotypes. Psychological Review, 102, 4-27.

Guéguen, N. (2002). Touch, awareness of touch, and compliance with a request. Perceptual and Motor Skills, 95, 355-360.

Henry, P. J., \& Sears, D. O. (2002). The symbolic racism 2000 scale. Political Psychology, 23, 253-283.

Joule, R.-V., \& Guéguen, N. (2007). Touch, compliance and awareness of tactile contact, Perceptual and Motor Skills, 104, 581-588. doi:10.2466/pms.104.2.581-588

Kurzban, R. (2001). The social psychophysics of cooperation: Nonverbal communication in a public goods game. Journal of Nonverbal Behavior, 25, 241-259. doi:10.1023/A:1012563421824

Lowery, B. S., Hardin, C. D., \& Sinclair, S. (2001). Social influence effects on automatic racial prejudice. Journal of Personality and Social Psychology, 81, 842-855. doi:10.1037/0022-3514.81.5.842

Mitchell, J. P., Nosek, B. A., \& Banaji, M. R. (2003). Contextual variations in implicit evaluation. Journal of Experimental Psychology: General, 132, 455-469. doi:10.1037/0096-3445.132.3.455

Monsour, M. (1992). Meanings of intimacy in cross- and same-sex friendships. Journal of Social and Personal Relationships, 9, 277-295.

Niedenthal, P. M., Barsalou, L. W., Winkielman, P., Krauth-Gruber, S., \& Ric, F. (2005). Embodiment in attitudes, social perception, and emotions. Personality and Social Psychology Review, 9, 184-211.

Nosek, B. A. (2005). Moderators of the relationship between implicit and explicit evaluation. Journal of Experimental Psychology: General, 134, 565-584. doi:10.1037/0096-3445.134.4.565

Page-Gould, E., Mendoza-Denton, R., Alegre, J. M., \& Siy, J. O. (2010). Understanding the impact of cross-group friendship on interactions with novel outgroup members. Journal of Personality and Social Psychology, 98, 775-793.
Patterson, M., Powell, J., \& Lenihan, M. (1986). Touch, compliance and interpersonal affect. Journal of Nonverbal Behaviors, 10, 41-50.

Pearce, C. M., Martin, G., \& Wood, K. (1995). Significance of touch for perceptions of parenting and psychological adjustment among adolescents. Journal of the American Academy of Child and Adolescent Psychiatry, 34, 160-167.

Pettigrew, T. F. (1998). Intergroup contact theory. Annual Review of Psychology, 49, 65-85.

Pettigrew, T. F., \& Tropp, L. R. (2006). A meta-analytic test of intergroup contact theory. Journal of Personality and Social Psychology, 90, 751-783. doi:10.1037/022-3514.90.5.751

Silverthorne, C., Noreen, C., Hunt, T., \& Rota, L. (1972). The effects of tactile stimulation on visual experience. Journal of Social Psychology, $88,153-154$

Smith, E. R., \& Henry, S. (1996). An in-group becomes part of the self: Response time evidence. Personality and Social Psychology Bulletin, $22,635-642$.

Smith, E. R., Seger, C. R., \& Mackie, D. M. (2007). Can emotions be truly group level? Evidence regarding four conceptual criteria. Journal of Personality and social Psychology, 93, 431.

Smith, E. R., \& Semin, G. R. (Eds.). (2008). Embodied grounding: Social cognitive, affective, and neuroscientific approaches. New York, NY: Cambridge University Press.

Summerhays, D. L., \& Suchner, R. W. (1978). Power implications of touch in male-female relationships. Sex Roles, 4, 103-110.

Tropp, L. R., \& Wright, S. C. (2001). Ingroup identification as the inclusion of ingroup in the self. Personality and Social Psychology Bulletin, $27,585-600$.

Turner, R. N., \& Crisp, R. N. (2010). Imagining intergroup contact reduces implicit prejudice. British Journal of Social Psychology, 49, 129-142. doi:10.1348/014466609X419901

Turner, R. N., Hewstone, M., \& Voci, A. (2007). Reducing explicit and implicit outgroup prejudice via direct and extended contact: The mediating role of self-disclosure and intergroup anxiety. Journal of Personality and Social Psychology, 93, 369-388. doi:10.1037/00223514.93.3.369

Turner, J. C., Hogg, M. A., Oakes, P. J., Reicher, S. D., \& Wetherell, M. S. (1987). Rediscovering the social group: A self-categorization perspective. Oxford, UK: Basil Blackwell.

Weiss, S. J., Wilson, P., St. John Seed, M., \& Paul, S. M. (2001). Early tactile experience of low birth weight children: Links to later mental health and social adaptation. Infant and Child Development, 10, 93-115. doi:10.1002/icd/236

Wright, S. C., Aron, A., McLaughlin-Volpe, T., \& Ropp, S. A. (1997). The extended contact effect: Knowledge of cross-group friendships and prejudice. Journal of Personality and Social Psychology, 73, 73-90. doi:10.1037/0022-3514.73.1.73 